\title{
EDUCAÇÃO AMBIENTAL, SUSTENTABILIDADE E CIÊNCIA: O PAPEL DA MÍDIA NA DIFUSÃO DE CONHECIMENTOS CIENTÍFICOS*
}

\author{
Environmental education, sustainability and science: \\ the role of media through the diffusion \\ of scientific knowledge
}

Samia Nascimento Sulaiman ${ }^{1}$

\begin{abstract}
Resumo: São problemas de ordem ambiental: aquecimento global, mudanças climáticas, escassez de recursos naturais, resíduo. Em resposta, têm sido gerados novos saberes no campo da ciência, tecnologia e educação chamada ambiental de modo a se proporem alternativas para que o homem possa relacionar-se com o ambiente de maneira sustentável, e a mídia tem contribuído sobremaneira na veiculação desses conhecimentos. $\mathrm{Na}$ imprensa escrita, revistas e jornais têm criado seções, suplementos, cadernos tematizando educação e meio ambiente. Produzida pela revista Carta Capital, desde 2006, a revista Carta na Escola busca difundir "atualidades em sala de aula", e de setembro de 2007 a agosto de 2008 publicou a série "Sustentabilidade na Escola", com dez artigos relacionando sustentabilidade, ciência e educação. A partir do referencial teórico-metodológico da análise dialógica do discurso, este artigo analisa o discurso da sustentabilidade baseado na difusão de conhecimentos científicos, proposto nessa série, e sua limitação enquanto estratégia de educação ambiental.
\end{abstract}

Palavras-chave: Sustentabilidade. Ciência. Educação ambiental. Mídia. Informação.

\begin{abstract}
Global warming, climatic changes, scarcity of natural resources, waste are problems of environmental order. As an answer new knowledge has been generated in the fields of science, technology and environmental education to propose sustainable way to relation between human being and environment, and the media contributes intensively in the propagation of these knowledge. The written press, magazines and newspapers have created sections, supplements, and special editions about education and environment, like Carta na Escola magazine, produced for the Carta Capital magazine, since 2006. Between 2007 September and 2008 August, it published the "Sustainability on the school" series with ten articles about sustainability, science and education. This article analyses the sustainability discourse through the diffusion of scientific knowledge. and focus the limitation of this propose to environmental education. We selected the dialogic language theory, or dialogism, like theoretical and methodological reference for discourse analysis.
\end{abstract}

Keywords: Sustainability. Science. Environmental education. Media. Information.

\footnotetext{
* Elaborado com base em Sulaiman (2010) .

${ }^{1}$ Licenciada e bacharel em Letras, doutoranda em Educação. Investigadora, TEIA-USP - Laboratório de Educação e Ambiente, Faculdade de Educação, Universidade de São Paulo. São Paulo, SP, Brasil.

$<$ samia.sulaiman@gmail.com>

Av. da Universidade, 308

Cidade Universitária, SP

05.508-900 


\section{Introdução}

A questão ambiental tem sido tema de debates em diversos eventos internacionais, como as conferências da Organização das Nações Unidas - ONU, ocorridas em Estocolmo (1972), Tbilisi (1977), Rio de Janeiro (1992), Thessaloniki (1997), Johannesburgo (2002). A necessidade de revisar a relação homem-ambiente tem ganhado atenção dos governantes, da iniciativa privada, da comunidade científica, da mídia e da sociedade civil.

Nessa perspectiva, têm emergido novos campos de conhecimento e ação frente à crise ambiental, como o chamado jornalismo ambiental, com "um enfoque mais ativamente educacional, esclarecedor e orientador das ações do público, sem didatismos banais" (VILAS BOAS, 2004, p. 8), bem como a educação ambiental, com a responsabilidade de educar para uma diferente e sustentável relação humana com o meio ambiente (CARVALHO, 2004).

Ambos os campos têm apoiado suas atividades na divulgação científica, entendida, de modo genérico, como uma atividade de difusão de conhecimentos científicos para a veiculação das informações científicas e tecnológicas ao público em geral, fora de seu contexto originário, por meio de um processo de recodificação. Segundo Bueno (1984), realiza-se a transposição de uma linguagem especializada para uma linguagem não especializada, com o objetivo de tornar o conteúdo acessível a uma vasta audiência.

Esse "trocar a ciência em miúdos", segundo Reis (1982), tem sido fundamental na compreensão da propalada crise ambiental contemporânea, muito relacionada tanto com os efeitos nocivos do desenvolvimento científico e tecnológico - gases de efeito estufa, lixo tóxico, insumos agrícolas - quanto com o avanço da tecnologia limpa para a sustentabilidade - biodiesel, reciclagem, agroecologia. Todas essas questões - educação, sustentabilidade e ciência - estiveram presentes na revista educativa Carta na Escola ${ }^{2}$ que, de setembro de 2007 a agosto de 2008, publicou dez artigos dentro da série "Sustentabilidade na Escola".

O presente artigo analisa os discursos da sustentabilidade propostos nessa série no que tange à relação entre difusão de conhecimentos científicos e educação ambiental, tendo como referencial teórico metodológico a análise dialógica do discurso, ou dialogismo, proposto pelos teóricos russos Mikhail Bakhtin, Valentin Voloshinov e Pavel Medvedev.

Imersa na Revolução Russa e no materialismo histórico, a teoria do dialogismo não considera a significação como dada, mas criada no processo de complexas relações dialógicas entre linguagem e sociedade. Nessa abordagem, o texto é objeto linguístico-discursivo, social e histórico; e a palavra não é uma unidade neutra: "cada palavra evoca um contexto ou contex-

\footnotetext{
${ }^{2}$ Lançada em 2006, a partir da revista Carta Capital, a revista Carta na Escola tem o intuito de apresentar, mensalmente (exceto janeiro e julho, período de recesso escolar), "atualidades em sala de aula", subtítulo da revista. Ela atinge professores de Ensino Médio (cerca de 20\% também lecionam no Ensino Fundamental), diretores, coordenadores e diretores de escola. Circula por meio de assinaturas, venda em bancas e por distribuição gratuita a escolas públicas. O conteúdo também está disponibilizado no site <www.cartanaescola.com.br>. (Dados e informações obtidos, por e-mail, com Marielle Brust, gerente executiva de negócios da Editora Confiança Ltda., responsável pelas revistas Carta Capital e Carta na Escola. [mensagem pessoal]. Mensagem recebida por<samia_22@yahoo.com.br>, em 16 jan. 2009.)

646

Ciência \&̊ Educacão, v. 17, n. 3, p. 645-662, 2011
} 
tos, nos quais ela viveu sua vida socialmente tensa; todas as palavras e formas são povoadas de intenções" (BAKHTIN, 2003, p. 100).

Este trabalho busca contribuir com o campo da educação ambiental, reconhecendo o papel dos meios de comunicação para a consciência e ação social em prol do meio ambiente e a necessária análise crítica sobre o discurso do conhecimento científico disseminado para esse fim.

\section{O papel dos meios de comunicação para a Educação Ambiental}

A escola é o lugar social da educação; no entanto, a educação escolar não é a única fonte de aprendizado do ser humano, é um momento no decorrer do processo múltiplo de sua socialização. Os espaços escolares, concebidos historicamente como espaços formais de educação, são uma parte do conjunto social de espaços com os quais convivemos e interagimos cotidianamente. Mesmo antes da internet e da globalização, McLuhan (1968, p. 17-18) afirmava que "a quantidade pura e simples de informações transmitidas pela imprensa, revistas, filmes, rádio e televisão excede, de longe, a quantidade de informações transmitidas pela instrução e pelos textos escolares".

Para o autor, os meios de comunicação são entendidos como extensões dos sentidos e das faculdades humanas; no entanto, são agentes "produtores de acontecimentos", e não agentes "produtores de consciência" (McLUHAN, 1968). Corroborando essa argumentação, Melo (1973, p. 123) afirma que o conteúdo veiculado pelos meios de comunicação "é refletido, digerido, analisado dentro dos grupos, vindo daí a adoção de opiniões e atitudes".

Essa perspectiva ampliada das fontes de informação e educação de nossa sociedade concebe o conceito de espaços educadores caros à Educação Ambiental, como afirma a nossa Política Nacional de Educação Ambiental ${ }^{3}$ (BRASIL, 1999). Segundo o Programa Municípios Educadores Sustentáveis do Ministério do Meio Ambiente - MES (2005), esses espaços demonstram alternativas viáveis para a sustentabilidade e são educadores porque estimulam ações individuais e conjuntas em prol da coletividade. Entre eles se inserem os meios de comunicação.

Carvalho (1989), em sua tese de doutorado intitulada "A temática ambiental e a escola de $1^{\circ}$ grau", apontou que dos 236 professores que devolveram o questionário de sua pesquisa, $121(51,27 \%)$ responderam afirmativamente à pergunta "Você já ouviu falar em Educação Ambiental?" Desses, 55,8\% haviam tido conhecimento sobre o termo "Educação Ambiental" a partir do que o autor denominou de sistema de comunicação social - imprensa escrita (26\%), televisionada $(18,2 \%)$, falada $(4,6 \%)$ e sem especificação $(7 \%)$.

A problemática ambiental, de fato, ganhou notoriedade e relevância social por meio da mídia, que rapidamente difundiu temas como: mudança climática, aquecimento global, biodiversidade, ambientalismo, sustentabilidade, cidadania ambiental. Especificamente no Brasil,

\footnotetext{
${ }^{3}$ Lei $9.795 / 1999$ - Art. $3^{\circ}$ Como parte do processo educativo mais amplo, todos têm direito à educação ambiental, incumbindo: IV - aos meios de comunicação de massa, colaborar de maneira ativa e permanente na disseminação de informações e práticas educativas sobre meio ambiente e incorporar a dimensão ambiental em sua programação.
} 
o jornalista Vilas Boas (2004) afirma que, com a Eco-92, criou-se a necessidade de se formarem jornalistas ambientais, aptos a discorrerem, com habilidade, conhecimento e visão sistêmica, sobre as temáticas que envolvem a causa ambiental; e de se fortalecer o chamado "jornalismo ambiental", que reconhece a contribuição informativa e formativa da mídia em prol de um novo projeto de civilização.

A plataforma das 21 ações prioritárias da Agenda 21 Brasileira (2004, p. 34) entende que a sustentabilidade exige uma dimensão comunicativa, e coloca a necessidade de se mobilizar o papel relevante de pedagogia social dos meios de comunicação - televisão, rádio e jornal - para veicular informação de interesse social, produzir campanhas voluntárias de esclarecimento, gerando notícias capazes de conscientizar a opinião pública sobre a necessária mudança de comportamentos.

Em consonância, o Programa Nacional de Educação Ambiental - PRONEA (2005) teve, como um de seus objetivos, "promover campanhas de Educação Ambiental nos meios de comunicação de massa, de forma a torná-los colaboradores ativos e permanentes na disseminação de informações e práticas educativas sobre o meio ambiente". É evidente o papel educativo da mídia, sobretudo frente à problemática ambiental contemporânea; porém, há que se analisar estratégias e conteúdos abordados.

Belmonte (2004), em seu artigo "Menos catástrofes e mais ecojornalismo", aponta a necessidade de cobertura de informações ambientais de qualidade e defende o debate público sobre a questão ambiental, e não apenas enfoques superficiais, baseados em sensacionalismo, terrorismo, colocando o meio ambiente na audiência do espetáculo, e não da educação.

Para Fonseca (2004), o papel do jornalismo ambiental não é repetir o já sabido com discursos generalistas numa militância panfletária, mas contribuir na difusão de informações pertinentes para que a sociedade possa, primeiramente, conhecer os problemas em suas complexidades, para, então, articular soluções. Veicular descobertas e inovações do campo da ciência e da tecnologia é uma possibilidade; contudo, sem tratar o discurso da mídia com neutralidade, nem o conhecimento científico com dogmatismo:

na educação escolar, a seleção entre os saberes e os materiais culturais tem por meta torná-los efetivamente transmissíveis e assimiláveis. Todavia, outros ecossistemas educativos irão determinar novas formas de produção, reprodução e apropriação do conhecimento. É o caso, por exemplo, dos espaços de educação não-formais e informais, como os museus de ciências, os programas educativos no rádio e na TV e os meios impressos como jornais e revistas. Nesses casos também os saberes científicos são selecionados e passam por processos de reorganização, tornando-os passíveis de sentido para o conjunto dos indivíduos. (KRASILCHIK; MARANDINO, 2004, p. 30)

Partindo dessas proposições, este artigo apresenta a análise dialógica do discurso da sustentabilidade veiculado pela revista Carta na Escola, por meio da série "Sustentabilidade na Escola", enfocando a relação entre educação ambiental e conhecimento científico proposta na série para que os professores, público-alvo da revista, abordem o tema da sustentabilidade em suas salas de aula. 
Educação Ambiental, sustentabilidade e ciência: ...

\section{O conhecimento científico no discurso midiático para a sustentabilidade}

Em setembro de 2007, a revista Carta na Escola lançou a série "Sustentabilidade na Escola", com o objetivo de "contribuir com novos pensares sobre velhos pesares", como afirmou o redator-chefe Ricardo Prado (2007). No entanto, a partir da análise dialógica do discurso, esses "novos" são resultado de um "velho" processo histórico e trazem as "vozes sociais" que permeiam o discurso da sustentabilidade.

A série - sob autoria de Evaristo Eduardo de Miranda, agrônomo, ecólogo e pesquisador da Embrapa Monitoramento por Satélite - foi composta de dez artigos (Quadro 1), sempre ocupando duas páginas, estilizadas como papel reciclado e com cabeçalho na cor verde. A primeira interpretação do corpus, num recorte quantitativo, partiu da análise de con-

Quadro 1. Títulos e leads* dos dez artigos da série "Sustentabilidade na Escola", publicados na revista Carta na Escola (set./2007 a ago./2008.

\begin{tabular}{|c|c|}
\hline Títulolárea/lead & Edição \\
\hline $\begin{array}{l}\text { O nascimento de um conceito ECOLOGIA Da Hipótese de Gaia ao aquecimento } \\
\text { global, o movimento ambiental fortaleceu-se em torno da ideia de nos tornarmos } \\
\text { autossustentáveis }\end{array}$ & setembro 2007 \\
\hline $\begin{array}{l}\text { Aquecimento global: dez respostas ECOLOGIA Tem muita gente por aí falando } \\
\text { o que não sabe sobre efeito estufa. Aqui você fica por dentro do assunto mais } \\
\text { quente do momento }\end{array}$ & outubro 2007 \\
\hline $\begin{array}{l}\text { O lixo não se desmancha no ar ECOLOGIA Lei de Lavoisier é fundamental para } \\
\text { a consciência ambiental: "Na natureza nada se cria, nada se perde, tudo se } \\
\text { transforma" }\end{array}$ & novembro 2007 \\
\hline $\begin{array}{l}\text { O desafio dos quatro "Rs" ECOLOGIA Precisamos urgentemente superar } \\
\text { resistências culturais e econômicas e aprender a reduzir, racionalizar, reutilizar e } \\
\text { reciclar }\end{array}$ & dezembro/ janeiro 2008 \\
\hline $\begin{array}{l}\text { Você tem sede de quê? ECOLOGIA Crescimento do mercado consumidor de } \\
\text { água aponta para a necessidade de se planejar melhor o uso desse mineral } \\
\text { essencial para a vida na Terra }\end{array}$ & fevereiro 2008 \\
\hline $\begin{array}{l}\text { Florestas sustentáveis ECOLOGIA O Brasil vem sendo criticado pelos campeões } \\
\text { do desmatamento, alijados da própria memória, e essa alienação acontece nos } \\
\text { bancos escolares }\end{array}$ & março 2008 \\
\hline $\begin{array}{l}\text { Pouco sustentáveis ENERGIA O Brasil é um dos campeões de energias } \\
\text { renováveis. Mas com a atual tecnologia, o que é bom para nós não seria aplicável } \\
\text { em escala mundial }\end{array}$ & abril 2008 \\
\hline $\begin{array}{l}\text { Cidades, escolas e moradias ECOLOGIA URBANA Casas e escolas } \\
\text { sustentáveis, ecologicamente corretas e de baixo custo são possíveis e estão na } \\
\text { base de cidades sustentáveis }\end{array}$ & maio 2008 \\
\hline $\begin{array}{l}\text { Como alimentar o mundo? ABASTECIMENTO O consumo de alimentos cresce } \\
\text { no Brasil e no mundo. A produção também, em especial a nossa. Mas o preço não } \\
\text { para de subir }\end{array}$ & junho/ julho 2008 \\
\hline $\begin{array}{l}\text { Nós como falsos vilões EFEITO ESTUFA Os países europeus têm aumentado } \\
\text { suas emissões de CO2. E o Brasil, injustamente, vem sendo cobrado como grande } \\
\text { poluidor }\end{array}$ & agosto 2008 \\
\hline
\end{tabular}

*Lead (ou a forma aportuguesada lide) representa a $1^{\text {a }}$ parte de uma matéria jornalística, posta em relativo destaque após o título, para fornecer ao leitor as informações básicas do texto e prender-lhe a atenção. 
teúdo sobre a abordagem do tema da sustentabilidade, que foi preponderantemente ligada à área de ciências, mais especificamente ao campo da ecologia. Categorizamos 5 unidades de análise: aquecimento global (30\%), agroenergia (50\%), água (20\%), resíduo $(20 \%)$ e produção alimentar $(10 \%)$.

A partir dessas cinco unidades de análise, passamos à segunda parte de interpretação dos dados, a qualitativa, por meio do referencial teórico-metodológico da análise dialógica do discurso sobre sustentabilidade. O dialogismo funda-se no amálgama indissociável entre linguagem e sociedade ${ }^{4}$. Nesse sentido, estabelecemos as relações dialógicas entre o discurso da sustentabilidade apresentado pelo corpus e os discursos expressos em documentos nacionais e internacionais de relevância para o campo da Educação e da Sustentabilidade.

As unidades de análise "aquecimento global" e "agroenergia" foram centrais na abordagem da sustentabilidade no corpus em análise $(80 \%)$. Na $1^{a}$ matéria da série, "Nascimento de um conceito", Evaristo Miranda (2007a) apresenta James Lovelock como um dos precursores da ideia da sustentabilidade em escala planetária, por sua Teoria de Gaia, apresentada simplificadamente no seguinte período: "Nessa teoria, a Terra é vista, como um superorganismo, como um imenso ser vivo que age de forma sistêmica" (MIRANDA, 2007a, p. 28).

$\mathrm{O}$ agrônomo argumenta que a mitigação do aquecimento global depende do conhecimento das leis de termodinâmica, sobretudo em relação ao sol como única fonte de energia renovável. Ele defende a "sustentabilidade verde", apoiada na agroenergia da plantação de cana-de-açúcar, de florestas e de biodiesel, que produz combustível renovável, menos poluente, créditos de carbono ${ }^{5}$ e redução na importação de combustíveis.

Ambas as unidades aparecem novamente na $2^{a}$ edição, "Aquecimento global: dez respostas". Nela Miranda (2007b) esclarece os processos naturais e históricos de variação das temperaturas da Terra, que "sempre ocorreram, porém, só nos últimos 200 anos os conhecimentos científicos permitiram uma visão dessas mudanças climáticas na história do planeta" (MIRANDA, 2007b, p. 24).

Além disso, desmistifica o alarmismo ligado ao efeito estufa:

Os principais gases do efeito estufa são, pela ordem de contribuição: CO2(60\%), CH4 (15\% a 20\%), N2O (6\%), O3, HFCs, PFCs e SF6. A preocupação atual é com alterações no efeito estufa e não com o efeito estufa propriamente dito. (MIRANDA, 2007b, p. 24)

\footnotetext{
${ }^{4}$ Bakhtin e seu Círculo propuseram um estudo inovador para sua época, ao relacionarem o funcionamento da linguagem com as práticas político-sociais em vigência na Rússia marxista, demonstrando como estas podiam se servir do uso da palavra para persuadir aqueles que se encontravam sob o seu domínio.

${ }^{5}$ Um exemplo dessa tendência está no Protocolo de Kyoto (1998), um tratado internacional em que cada país se compromete a reduzir a sua emissão de gases que provocam o efeito estufa, considerados como causa antropogênica do aquecimento global. Essa redução foi estimulada pela proposta do Mecanismo de Desenvolvimento Limpo (MDL), instrumento financeiro do protocolo que induz à redução de emissões em países enriquecidos e grandes poluidores desde que financiem, em países "empobrecidos", projetos de "sequestro" de carbono da atmosfera.
} 
O autor retoma a questão da produção de energia:

Pode-se agir essencialmente sobre causas humanas. São dois caminhos: reduzir as causas e adaptar-se às mudanças. Para reduzir a emissão de gases de efeito estufa é fundamental trocar o carvão e o petróleo por energias renováveis, como o etanol, por exemplo. (MIRANDA, 2007b, p. 25)

"Aquecimento global" e "agroenergia" também são relacionados na $10^{a}$ edição "Nós como falsos vilões" -, em que Miranda (2008f) defende a posição privilegiada do Brasil quanto ao baixo volume de emissão de gases de efeito estufa:

Considerando-se quatro indicadores homogêneos de comparação: o valor absoluto das emissões de $\mathrm{CO}_{2}$ e os valores relativos por habitante, por quilômetro quadrado e por riqueza produzida o Brasil está entre os que menos contribuem com esse fenômeno, segundo os dados de 2005 da agência federal norte-americana Energy Information Administration e do Balanço Energético Nacional. (MIRANDA, 2008f, p. 24)

Com esse discurso, o autor também critica o não-reconhecimento dessa liderança brasileira frente ao aquecimento global e o discurso errôneo de dois importantes espaços educadores: "A agricultura brasileira garante 28,5\% dessa energia renovável. Existe, porém, uma injustificável vitimização do País neste tema, cultivada inclusive pela mídia brasileira e em salas de aula, aqui e no exterior" (MIRANDA, 2008f, p. 25). O autor enfatiza, portanto, que tanto os meios de comunicação como as instituições de ensino não têm acompanhado os avanços no campo da ciência, o que, de certa maneira, justifica a abordagem cientificista da série.

O recorte isolado da "agroenergia" dá-se na $6^{a}$ edição - "Florestas sustentáveis" -, relacionado a patrimônio natural. $\mathrm{O}$ autor apoia a sustentabilidade na lógica econômica, criticando o atraso brasileiro em não valorar as florestas como capital natural. Sem gestão e investimentos, ele prevê escassez de madeira, carvão e lenha para atender aos mais variados setores, o que ele denominou de "apagão florestal":

Um bom começo para ampliar a sustentabilidade florestal seria repensar o papel das florestas na economia e na vida do País, facilitando o plantio para a produção comercial de energia e madeira - principalmente nas áreas de pastagem da Amazônia - e protegendo adequadamente o valioso patrimônio natural. (MIRANDA, 2008b, p. 51)

Essa abordagem prossegue na $7^{a}$ edição - "Pouco sustentáveis". Dentro do argumento científico, Miranda (2008c) afirma que "A energia renovável é solar", e está na flora, o que é mais um argumento favorável à "sustentabilidade verde". Contudo, apesar de abundantes e de qualidade ambiental, as energias renováveis apresentam muitas desvantagens, segundo o autor, que limitam e limitarão seu emprego futuro, e sobre as quais pouco se reflete. 
A primeira desvantagem apresentada é a fraca densidade energética da agroenergia da cana-de-açúcar:

[...] se toda cana-de-açúcar do Brasil fosse transformada em energia o que é impossível - sua palha, colmos, bagaço, álcool e açúcar representariam o equivalente à produção de 1 milhão de barris de petróleo, enquanto a produção nacional ultrapassa os 2 milhões. (MIRANDA, 2008c, p. 28)

A segunda é a intermitência das agroenergias eólica, solar e hidrelétrica, que variam em função de meteorologia, luminosidade e disponibilidade de chuvas, respectivamente, e a última desvantagem relaciona-se ao atraso tecnológico brasileiro.

O autor deixa evidente sua perspectiva de "sustentabilidade na escola": ensino e apreensão sobre conhecimentos científicos e avanços tecnológicos. No entanto, não se pode defender um processo educativo baseado na simples transmissão e/ ou assimilação de conhecimentos científicos sobre o ambiente, partindo da premissa de que esses conhecimentos são suficientes para se construir uma relação mais adequada dos sujeitos com o ambiente. Como elucidam Krasilchik e Marandino (2004), a informação do campo da ciência prescinde de apropriação crítica sobre fatores sociais, políticos, econômicos, éticos, envolvidos na produção do saber científico, e suas implicações na sociedade, o que as autoras definem como alfabetização científica:

O conhecimento e as informações são a base necessária para analisar questões controversas que incluem conflitos de interpretações e decisões, dependentes de valores pessoais e sociais. Preparar o cidadão para pensar sobre as questões que permitem várias respostas - muitas vezes conflitantes - demanda que ele seja alfabetizado em ciências. Considerando que, de um lado, há um crescimento marcadamente amplo da ciência e da tecnologia e, de outro, situações que agravam a miséria, a degradação ambiental e os conflitos étnicos, sociais e políticos, é preciso que os cidadãos estejam em condições de usar seus conhecimentos para fundamentar suas posições e ações. (KRASILCHIK; MARANDINO, 2004, p. 34)

Sustentabilidade, no corpus analisado, é resultado de investimento tecnocientífico e de gestão ambiental. No entanto, a defesa da agricultura moderna, ou do agronegócio, apoia-se na produção em larga escala para um grande mercado consumidor, e desconsidera a biossociodiversidade. Esse é o cenário da circularidade, onde tudo possa continuar sendo feito do mesmo modo, desde que de um outro jeito (SILVA, 1996).

Dessa forma, a população dominar o conhecimento científico, por meio de uma vulgarização acrítica do discurso científico, também significa manter o poder da ciência sobre a sociedade e legitimar seu caráter de incontestabilidade e infalibilidade, o que deve ser avaliado e superado de acordo com os princípios da Educação Ambiental ${ }^{6}$ : 
Em Educação Ambiental, ciência e formação crítica precisam se relacionar de modo a compreendermos sob que condições o saber científico se desenvolveu e a favor do que e de quem, nos apropriando da base instrumental e reflexiva necessária para a educação, para alteração objetiva das condições de vida da população e reversão do processo de degradação e exploração das demais espécies e da natureza como um todo, rompendo com dogmas e obstáculos à liberdade humana. (LOUREIRO, 2004, p. 30)

A abordagem dos temas "aquecimento global" e "agroenergia" na série "Sustentabilidade na Escola" foi essencialmente científica, e ela dirigiu-se ao profissional da educação, público-alvo do periódico. No entanto, esse profissional precisa compreender que o ensino e a divulgação de Ciências devem ser encarados, pelo menos, a partir de duas dimensões: em uma, considerar as implicações sociais do desenvolvimento científico e tecnológico; e, em outra, analisar as relações da evolução da ciência e tecnologia e da qualidade e do modo de vida em diferentes comunidades. Ou seja, avaliar "as diferentes facetas relacionadas às causas, possibilidades e limitações e perspectivas da ciência e tecnologia como processo, como produto e como instituição social" (KRASILCHIK; MARANDINO, 2004, p. 42).

A unidade de análise "água" surge na $3^{a}$ edição - "O lixo não se desmancha no ar". Miranda (2007c, p. 20) identifica que "os cursos d'água são considerados um enorme depósito, um digestor natural de matérias cloacais", e combate essa crença por meio da premissa da Lei da Conservação de Massas (Lei ou Princípio de Lavoisier): "Na natureza nada se cria, nada se perde, tudo se transforma" (MIRANDA, 2007c, p. 20).

Para o agrônomo, essa frase ainda é pouco conhecida no Brasil e deveria ser a base de todos os cursos de Educação Ambiental, pois "a ciência e a razão devem combater os mitos e as mistificações, mesmo quando são pretensamente ecológicos, revolucionários ou a favor do meio ambiente" (MIRANDA, 2007c, p. 21). Segundo ele, o conhecimento científico é a forma de pensar e agir na sustentabilidade:

Por isso, também é errado, mesmo se com boas intenções, fazer afirmações alarmistas do tipo: a água do mundo está acabando! Não somos capazes nem de criar quantidades significativas de água nem de fazê-la desaparecer. A água torna-se escassa em conseqüência do aumento da demanda ou do uso inadequado. Ela fica imprópria ao consumo huma-

\footnotetext{
${ }^{6}$ Segundo preâmbulo do "Tratado de educação ambiental para sociedades sustentáveis e responsabilidade global” (1992), produzido no Fórum Global das Ongs durante a Eco-92: "Consideramos que a Educação Ambiental para uma sustentabilidade equitativa é um processo de aprendizagem permanente, baseado no respeito a todas as formas de vida. Tal educação afirma valores e ações que contribuem para a transformação humana e social e para a preservação ecológica. Ela estimula a formação de sociedades socialmente justas e ecologicamente equilibradas, que conservam entre si relação de interdependência e diversidade. Isto requer responsabilidade individual e coletiva em nível local, nacional e planetário”. Disponível em: <http:// www.vitaecivilis.org.br/anexos/EDUCACAO_AMBIENTAL_35.PDF>. Acesso em: 05 fev. 2008.
} 
no e animal devido à poluição, mas é a mesma quantidade de água existente no planeta, há milhões de anos. (MIRANDA, 2007c, p. 21)

Já na $5^{a}$ edição - "Você tem sede de quê?", o enfoque é a qualidade das águas do abastecimento público, das fontes e das garrafas. Miranda (2008a) apresenta a composição da água por dois gases, citando as descobertas do francês Antoine Lavoisier e do italiano Alessandro Volta. Em seguida, descreve os três estados da água e nove indicadores da qualidade das águas ${ }^{7}$. O agrônomo problematiza a gestão do recurso hídrico (da extração ao fornecimento), colocando superficialmente questões como: a transposição do Rio São Francisco, a "produção" da água e o tratamento de efluentes, a expansão de sistemas de reúso e a cobrança da água proposta pelos comitês gestores de bacia.

A quarta unidade de análise, "resíduo", é abordada na $4^{a}$ matéria da série - "O desafio dos quatro 'Rs". A questão central é a gestão sustentável dos recursos naturais que deveria incorporar os 4 Rs (reduzir, racionalizar, reutilizar e reciclar) desde a produção ao resíduo, subsidiada pelo Princípio de Lavoisier de Conservação da Matéria.

Por um lado, Miranda pondera a vantagem sustentável do uso dos computadores "Teoricamente, reduzem-se o uso de papel, de produtos químicos fotográficos e o gasto de combustível com viagens (de trabalho, de casa para o escritório e até reuniões internacionais), entre outros" (MIRANDA. 2007d, p. 30). Por outro, relaciona tecnologia com resíduo, por meio dos neologismos E-lixo e E-polvição, o que o autor chama de reverso da moeda: "a confecção dos componentes dos computadores demanda materiais tóxicos que são, além de poluentes, bioacumulativos na teia alimentar e altamente persistentes no ambiente" (MIRANDA. 2007d, p. 30).

Essa temática também é discutida na $8^{a}$ edição da série - "Cidades, escolas e moradias", que aborda construções sustentáveis. Dentro da arquitetura, é explicitada a noção de sustentabilidade ligada ao reaproveitamento de resíduos inertes, uso de materiais menos poluidores - como o cimento verde, o CP II e III -, eficiência no uso e reúso da água, energia renovável, na lógica da diminuição do impacto ambiental:

$\mathrm{Na}$ casa sustentável, a bioarquitetura e a bioconstrução valorizam os recursos naturais locais, aproveitam materiais oriundos da reciclagem de edificações demolidas, evitam produtos tóxicos e embalagens descartáveis, cuidam da gestão da água da chuva e das águas residuais, utilizam a energia solar, integram as áreas externas e áreas verdes com o funcionamento interior das residências e adotam sistemas construtivos sustentáveis. (MIRANDA, 2008d, p. 28)

\footnotetext{
${ }^{7}$ Os nove indicadores que compõem o Índice de Qualidade das Águas (IQA) são: oxigênio dissolvido (OD), demanda bioquímica de oxigênio (DBO), coliformes fecais, temperatura, $\mathrm{pH}$, nitrogênio total, fósforo total, sólidos totais e turbidez (MIRANDA, 2008a).
} 
A última e menos abordada unidade de análise é a "produção alimentar", que aparece na $9^{a}$ matéria. Com um título questionador "Como alimentar o mundo?", o articulista descreveu um cenário negativo da atualidade para a garantia alimentar da sociedade contemporânea: número cada vez menor de agricultores, crescimento econômico global, incremento da renda das famílias, ocidentalização do hábito alimentar de asiáticos e africanos, e o uso de matériasprimas agrícolas para a produção de biocombustível. Mas nenhuma dessas causas foi discutida, nem mesmo os biocombustíveis que foram defendidos $-80 \%$ dos textos, sob as unidades de análise "aquecimento global" e "agroenergia" - sem uma análise crítica e complexa sobre seu impacto para a produção agrícola de alimentos e ração animal.

Ao contrário, o articulista apresenta três grandes caminhos para atender à demanda por alimentos, nem todos com a mesma sustentabilidade: ampliar a área cultivada, aumentar a produtividade da agricultura e implementar novas opções de produção. Nessas 2 últimas propostas, Miranda (2008e) indica a agricultura orgânica e de organismos geneticamente modificados (OGMs).

A produção de transgênicos tem maior abordagem na matéria, tanto quantitativa, com o dobro do espaço dos orgânicos, quanto qualitativa, com diversas justificativas de sustentabilidade: diminuição do uso de agrotóxicos, menores custos e maior produção. Todavia, não foram enfatizados os impactos - para o ambiente e para a saúde humana - da produção de um elemento modificado; o alto custo da importação de sementes; a uniformização vegetal pela monocultura e pelo agronegócio; bem como a soberania do conhecimento tecnocientífico sobre as culturas agrícolas nativas.

Sobre esse impacto, Shiva (2005) observa como a biotecnologia na Ásia processou uma política de extinção do saber e cultura locais e apresentou a monocultura como único sistema produtivo e rentável, pelo seu valor no mercado: as variedades nativas, ou espécies autóctones, foram consideradas como sementes primitivas; enquanto as variedades criadas via alta tecnologia, avançadas ou da elite.

A monocultura agrícola, dessa forma, descarta uma pluralidade de caminhos para se conhecer e interagir com a natureza, o que a autora define como "monocultura da mente". Nesse cenário, o sistema ocidental é considerado o único, verdadeiro e universal, afirmando uma política de trânsito de capital e conhecimento dos países centrais para os periféricos ou, como identifica a autora, de transferência dos países detentores de tecnologia para os detentores de biodiversidade.

Assim, à reflexão crítica sobre o conhecimento científico e suas implicações na sociedade, soma-se a reflexão sobre seu papel na construção da ideia-ação de sustentabilidade. No Dicionário Michaelis (1998), sustentabilidade significa "qualidade de sustentável", e este adjetivo refere-se ao "que pode ser sustentado". Segundo Bourdieu (2000, p. 15), "o que faz o poder das palavras e das palavras de ordem, poder de manter a ordem ou de a subverter, é a crença na legitimidade das palavras e daquele que as pronuncia, crença cuja produção não é da competência das palavras". 
A palavra "sustentabilidade" populariza-se e legitima-se com o "Relatório Brundtland, nosso futuro comum" ", sendo relacionada a desenvolvimento. O então desenvolvimento sustentável é "aquele que atende as necessidades do presente sem comprometer a possibilidade de as gerações futuras atenderem a suas próprias necessidades" (COMISSÃO MUNDIAL SOBRE MEIO AMBIENTE E DESENVOLVIMENTO, 1988, p. 46), tendo dois conceitoschave:

. O conceito de "necessidades", sobretudo as necessidades essenciais dos pobres do mundo, que devem receber a máxima prioridade;

- A noção de limitações que o estágio da tecnologia e da organização social impõe ao meio ambiente, impedindo-o de atender às necessidades presentes e futuras (COMISSÃO MUNDIAL SOBRE MEIO AMBIENTE E DESENVOLVIMENTO, 1988, p. 46).

O primeiro conceito centraliza a pobreza como uma das principais causas da degradação ambiental, e não toca na discussão sobre a diminuição do materialismo e do consumismo. Nesse aspecto, legitima-se o próprio capitalismo e a expansão constante do sistema industrial. O segundo conceito intensifica as políticas de investimento em ciência e tecnologia sustentáveis e sua transferência.

Necessidades e limitação tecnológica fazem referência direta a controle social e natural dos países periféricos. Essa é a linha que permeia a série "Sustentabilidade na Escola": de um lado, pelos transgênicos que, com produção em larga escala a custo reduzido, resolvem as "necessidades"; de outro, pela agroenergia que, com investimento e importação de conhecimento, supera a "limitação tecnológica".

Para Lima (2003), temos um "conservadorismo dinâmico" que representa obstáculo à concepção e implementação de uma proposta complexa e transformadora de sustentabilidade, que não seja liderada pelo mercado, não se apoie em mudanças técnicas e demográficas, não seja reducionista e, portanto, necessariamente insustentável.

A análise dialógica do discurso da sustentabilidade veiculada na série "Sustentabilidade na Escola", a que procedemos neste artigo, evidencia, portanto, a limitação de se difundirem conhecimentos científicos e avanços tecnológicos para defender um processo de sustentabilidade sem uma abordagem crítica sobre a quem se dirige esse discurso e quem se beneficia com ele, sobretudo quando se trata de um discurso construído e direcionado para a escola, como é o caso do corpus em análise.

${ }^{8}$ O "Relatório Brundtland" foi produzido em 1987 pela Comissão Mundial de Meio Ambiente e Desenvolvimento. Foi um documento em resposta à década anterior: a necessidade de um critério e de princípios comuns (Declaração de Estocolmo, 1972); bem como a superação da contradição entre salvação do planeta e desenvolvimentismo (MEADOWS, 1978). 
Educação Ambiental, sustentabilidade e ciência: ...

\section{Educação ambiental e sustentabilidade pela apropriação crítica do conhecimento científico}

A sociedade tem demonstrado ansiar pela partilha do saber da ciência e da tecnologia, cujas descobertas reflitam na melhoria da qualidade de vida, do ambiente e da saúde, para se alcançar a almejada sustentabilidade. Assim, além do caráter informativo, a divulgação científica apresenta uma função educativa, na formação de opinião pública qualificada, assumindo os contornos de uma prática fundamentalmente comunicativa de vulgarização e mediação. Nesse cenário, tem-se configurado um novo mercado de produção de revistas educativas que tematizam, entre outros aspectos, a formação científica e ambiental dos professores, ligada à temática da sustentabilidade, como é o caso da revista Carta na Escola, aqui em estudo.

No entanto, a divulgação científica é um recurso de mídia que opera como uma força de reconhecimento e legitimação dos círculos de saber, conferindo à atividade científica um lugar de prestígio e poder. O conhecimento científico é historicamente arquitetado, "estando implicado nas relações sociais, políticas, econômicas e ideológicas das sociedades onde é produzido" (KRASILCHIK; MARANDINO, 2004, p. 20).

Por isso, embora seja comum advogar a natureza conciliatória da divulgação científica que cumpriria a função social de aproximar o homem leigo dos saberes e conhecimentos historicamente excluídos da laicidade e, cada vez mais, restritos a comunidades fechadas, "é preciso ver na atividade de divulgação mais do que uma forma de lançar pontes de trânsito entre o saber institucionalizado e o não-saber laico" (ZAMBONI, 1997, p. 63).

Nos dez artigos da série "Sustentabilidade na Escola", apresenta-se o papel da ciência e da tecnologia para a construção da "sustentabilidade verde". Nesse sentido, a educação ambiental proposta apoia-se na legitimidade do conhecimento científico, representado pelas leis da termodinâmica, colocando a agricultura moderna como caminho para a sustentabilidade no Brasil. Como referência, está a eficiência na produção de alimentos e de energia limpa e renovável, que se materializa, nas explanações de Evaristo Miranda, nos alimentos transgênicos e na agroenergia.

No entanto, o articulista coloca a responsabilidade dessa nova forma de produzir e consumir sobre o "livre-arbítrio" do consumidor, sem considerar as desigualdades sociais, culturais e econômicas que limitam a escolha individual: "Caberá ao consumidor, ao cidadão informado e ao estudante bem formado, ciente de sua responsabilidade ambiental, indicar suas preferências e pagar o preço necessário para atender suas exigências e hábitos de consumo" (MIRANDA, 2008e, p. 33). À Educação Ambiental importa a relação entre ensino científico e cidadania:

[...] em uma delas, o aprendizado não pode ser pleno e completo sem considerar as implicações sociais do desenvolvimento científico e tecnológico; e outra, é imperativo analisar as relações da evolução da ciência e tecnologia e da qualidade e do modo de vida em diferentes comunidades. Embora haja uma clara conjunção desses processos, a educação - qualquer que seja o nível e a instância em que se realize deverá fazer com que os participantes analisem as diferentes facetas relacionadas às causas, possibilidades e limitações e perspectivas da 
ciência e tecnologia como processo, como produto e como instituição social. (KRASILCHIK; MARANDINO, 2004, p. 42)

$\mathrm{Na}$ série analisada, foram enfatizadas a eficiência tecnológica, a gestão ambiental e as mudanças de comportamento, com forte grau de normatividade e prescritividade, abordagem que implica propostas de Educação Ambiental centradas na formação econômica e técnica, não ética (CARVALHO, 2004; LIMA, 2003).

Esse é o problema identificado no corpus: um discurso da sustentabilidade, voltado ao público docente, com alto grau de cientificismo e comportamentalismo, que se materializou, inclusive, na linguagem, com novos termos para velhos pensamentos, como: "agroenergia", para manter a monocultura, o agronegócio e a exportação de commodities; "florestas energéticas" e "apagão florestal", para valorar o meio ambiente e veicular a noção de capital natural; "sustentabilidade verde", para sustentar a produção energética pelo agronegócio.

O papel da escola em relação à sustentabilidade, segundo a série analisada, é informar, aos alunos, sobre as inovações tecnológicas em relação ao aquecimento global, ao efeito estufa, à produção de energia e alimentos, à gestão da água e dos resíduos, desmistificando a problemática ambiental pelo conhecimento científico.

É inegável o potencial e a contribuição da ciência, e isso deve fazer parte do processo educacional. No entanto, temos um conceito limitado de ciência, pretensamente neutra e objetiva, o que a torna dogmática, já que indiscutível. Além disso, problematizamos a questão do otimismo tecnológico que se coloca como panaceia para todos os males, principalmente os ambientais, e "recurso mágico" capaz de inventar soluções para qualquer problema interveniente.

Ressaltamos, portanto, que a série traz uma abordagem sobre sustentabilidade que precisa ser analisada e aprofundada pelo professor em sala de aula. O material pode ser utilizado como exemplo de uma visão fragmentada sobre a questão ambiental e suas consequências na formação da opinião pública, já que foi veiculado em um meio de comunicação de massa.

Aos profissionais da educação, público da revista, cabe superarem processos educativos ligados à assimilação passiva de conteúdos científicos para simples mudanças comportamentais dos educandos, propondo reflexões sobre que princípios e proposições alicerçam as descobertas da ciência e as inovações tecnológicas. A eles também cabe a responsabilidade de discutirem os preceitos e propostas de sustentabilidade para que pese tanto o desenvolvimento tecnológico, científico e econômico quanto o desenvolvimento social, cultural e ambiental.

\section{Considerações finais}

Este artigo buscou evidenciar o papel educativo dos meios de comunicação para a difusão de informações e conhecimentos científicos que sejam alternativos ao paradigma da degradação ambiental em que vem se apoiando o desenvolvimento das sociedades modernas. Todavia, esse papel adquire excessiva responsabilidade quando direcionado ao público docente, como o corpus aqui analisado.

A ciência contribui sobremaneira na produção de conhecimento e inovação para formas mais sustentáveis de produção e consumo. No entanto, a ela deve-se somar, principal- 
Educação Ambiental, sustentabilidade e ciência: ...

mente no campo educacional, a reflexão sobre os princípios ideológicos que lhe fundamentam e sobre sua relação com uma realidade de disparidades sociais, culturais e econômicas, que tomou dimensão planetária.

O corpus analisado informa, mas também "deforma", se não é entendido a partir de uma reflexão crítica. A mídia informa, mas a formação crítica passa por outros espaços e momentos que permitam a construção de conhecimento e opinião. Evidenciamos um duplo movimento: é importante que a escola esteja aberta às atualidades, e os meios de comunicação são uma fonte de informações; mas os professores precisam analisar, com profundidade, essas informações.

O papel da escola em relação à sustentabilidade é informar, aos alunos, as descobertas científicas e as inovações tecnológicas, e analisar suas lógicas de produção e seus impactos econômicos e socioculturais; bem como evidenciar e comparar outras formas de pensar e agir sobre o meio ambiente que não sejam submissas ao dogma de "salvação" pela ciência e que também estejam sob o paradigma da sustentabilidade.

\section{Referências}

AGENDA 21 brasileira: ações prioritárias. 2. ed. Brasília: Ministério do Meio Ambiente, 2004. Disponível em: <http://api.ning.com/files/fjONV4GvaLzXhq0bhoUuGHVnl FCn9Q82m4Re9-fJTwLewXvjphPxET5m2Lxtoj*CDZziGUivtf5zQb7IBmateqc CTfqA8hAo/Agenda21BrasileiraAes.pdf>. Acesso em: 11 dez. 2008.

BAKHTIN, M. Estética da criação verbal. 4. ed. São Paulo: Martins Fontes, 2003.

BELMONTE, R. V. Cidades em mutação: menos catástrofes e mais ecojornalismo. In: VILAS BOAS, S. V. (Org.). Formação \& informação ambiental: jornalismo para iniciados e leigos. São Paulo: Summus, 2004. p. 15-48.

BOURDIEU, P. O poder simbólico. 3. ed. Rio de Janeiro: Bertrand Brasil, 2000.

BRASIL. Lei no 9.795, de 27 de abril de 1999. Dispõe sobre a educação ambiental, institui a Política Nacional de Educação Ambiental e dá outras providências. Diário Oficial da União, Brasília, DF, 28 abr. 1999. Seção 1, p. 1. Disponível em: <http://www2.camara. gov.br/legin/fed/lei/1999/lei-9795-27-abril-1999-373224-norma-pl.html>. Acesso em: 11 dez. 2008.

BUENO, W. C. Jornalismo científico no Brasil: os compromissos de uma prática dependente. 1984. 364f. Tese (Doutorado em Jornalismo) - Escola de Comunicação e Artes, Universidade de São Paulo, São Paulo, 1984.

CARVALHO, I. C. M. Educação ambiental: a formação do sujeito ecológico. São Paulo: Cortez, 2004. 
Sulaiman, S. N.

CARVALHO, L. M. Temática ambiental e a escola de primeiro grau. 1989. 286f. Tese (Doutorado em Educação) - Faculdade de Educação, Universidade de São Paulo, São Paulo, 1989.

COMISSÃO MUNDIAL SOBRE MEIO AMBIENTE E DESENVOLVIMENTO.

Nosso futuro comum. Rio de Janeiro: FGV, 1988.

DECLARAÇÃO de Estocolmo. Disponível em: < http://www.mma.gov.br/estruturas/ agenda21/_arquivos/estocolmo.doc>. Acesso em: 4 out. 2008.

DECLARAÇÃO de Tbilisi. Disponível em: <http://www.gdrc.org./uem/ee/tbilisi.html>. Acesso em: 16 fev. 2009.

FONSECA, A. A. Água de uma fonte só: a magnitude do problema em uma experiência concreta. In: VILAS BOAS, S. V. (Org.). Formação \& informação ambiental: jornalismo para iniciados e leigos. São Paulo: Summus, 2004. p. 111-148.

KRASILCHIK, M.; MARANDINO, M. Ensino de ciências e cidadania. São Paulo: Moderna, 2004.

LIMA, G. F. C. O discurso da sustentabilidade e suas implicações para a educação.

Ambiente e Sociedade, Campinas, v. 6, n. 2, p. 99-119, 2003.

LOUREIRO, C. F. B. Trajetórias e fundamentos da educação ambiental. São Paulo: Cortez, 2004.

McLUHAN, M. Revolução na comunicação. Rio de Janeiro: Zahar Editores, 1968.

Os meios de comunicação como extensões do homem. São Paulo: Cultrix,

1969.

MEADOWS, D. H. et al. Limites do crescimento. 2. ed. São Paulo: Perspectiva, 1978.

MELO, J. M. Comunicação social: teoria e pesquisa. Petrópolis: Vozes, 1973.

MICHAELIS, H. Moderno dicionário da língua portuguesa. São Paulo: Melhoramentos, 1998.

MIRANDA, E. E. Sustentabilidade na escola 1: o nascimento de um conceito. Carta na Escola, São Paulo, n. 19, p. 28-29, set. 2007a.

Sustentabilidade na escola 2: aquecimento global: dez respostas. Carta na Escola, São Paulo, n. 20, p. 24-25, out. 2007b.

Sustentabilidade na escola 3: o lixo não se desmancha no ar. Carta na Escola, São Paulo, n. 21, p. 20-21, nov. 2007c.

Sustentabilidade na escola 4: o desafio dos quatro "Rs". Carta na Escola, São

Paulo, n. 22, p. 30-31, dez. 2007d.

Sustentabilidade na escola 5: você tem sede de quê? Carta na Escola, São Paulo, n. 23 , p. $32-33$, fev. 2008a.

660

Ciência \&̊ Educacão, v. 17, n. 3, p. 645-662, 2011 
Educação Ambiental, sustentabilidade e ciência: ...

Sustentabilidade na escola 6: florestas sustentáveis. Carta na Escola, São Paulo, n. 24 , p. 50-51, mar. 2008b.

Sustentabilidade na escola 7: pouco sustentáveis. Carta na Escola, São Paulo, n. 25 , p. 28-29, abr. 2008 c.

Sustentabilidade na escola 8: cidades, escolas e moradias. Carta na Escola, São Paulo, n. 26, p. 28-29, maio 2008d.

. Sustentabilidade na escola 9: como alimentar o mundo. Carta na Escola, São Paulo, n. 27, p. 32-33, jun. 2008e.

Sustentabilidade na escola 10: nós como falsos vilões. Carta na Escola, São Paulo, n. 28, p. 24-25, ago. 2008f.

PRADO, R. Tão longe, tão perto. Carta na Escola, São Paulo, n. 18, p. 4, ago. 2007.

PROGRAMA Municípios Educadores Sustentáveis. 2. ed. Brasília: Ministério do Meio Ambiente, 2005. Disponível em: <http://www.scribd.com/doc/4957819/Municipioseducadores-sustentaveis-cartilha>. Acesso em: 4 ago. 2008.

PROGRAMA Nacional de Educação Ambiental. 3. ed. Brasília: Ministério do Meio Ambiente, 2005. Disponível em: <http://portal.mec.gov.br/secad/arquivos/pdf/ educacaoambiental/pronea3.pdf > . Acesso em: 14 out. 2008.

PROTOCOLO de Kyoto de la Convención Marco de las Naciones Unidas sobre el Cambio Climático. Disponível em: <http://www.cne.es/cne/doc/interes/protocolo_kyoto.pdf>. Acesso em: 10 nov. 2009.

REIS, J. O caminho de um divulgador. Ciência e Cultura, São Paulo, v. 34, n. 6, p. 800-816, 1982.

SHIVA, V. Monoculturas da mente: perspectivas da biodiversidade e da biotecnologia. São Paulo: Gaia, 2005.

SILVA, T. D. O cidadão e a coletividade: as identificações produzidas no discurso da educação ambiental. In: TRAJBER, R.; MANZOCHI, L. H. (Coords.). Avaliando a educação ambiental no Brasil: materiais impressos. São Paulo: Gaia, 1996. Disponível em: < http://www.ecoar.org.br/avaliando2/downloads/EA8-Cidadao.doc $>$. Acesso em: 15 nov. 2008.

SULAIMAN, S. N. Educação ambiental à luz da análise do discurso da sustentabilidade: do conhecimento científico à formação cidadã. 2010. 132f. Dissertação (Mestrado) - Programa: Cultura, Educação e Organização, Faculdade de Educação, Universidade de São Paulo, São Paulo, 2010. Disponível em: <http://www.teses.usp.br/ teses/disponiveis/48/48134/tde-11062010-112658/en.php>. 
Sulaiman, S. N.

TRATADO de educação ambiental para sociedades sustentáveis e responsabilidade global. Disponível em: < http://portal.mec.gov.br/secad/arquivos/pdf/educacaoambiental/ tratado.pdf>. Acesso em: 5 fev. 2008.

VILAS BOAS, S. (Org.). Formação \& informação ambiental: jornalismo para iniciados e leigos. São Paulo: Summus, 2004.

ZAMBONI, L. M. S. Heterogeneidade e subjetividade no discurso da divulgação científica. 1997. 168f. Tese (Doutorado em Linguística) - Instituto de Linguagem, Universidade Estadual de Campinas, Campinas, 1997. Disponível em: <http:/ / www.cciencia.ufrj.br/Publicacoes/Dissertacoes/lilian_resumo_tese.PDF>.

Artigo recebido em 09/09/2010. Aceito em 17/03/2011. 